Lolume 4 Issue 1(2021) 12-17
Longda Xiokan:

\title{
Analisis Dialek Mandarin Tiongkok Dan Dialek Mandarin Taiwan Dari Film The Ex-File 3 : The Return Of The Exes (Tiongkok) Dan Film Our Times (Taiwan)
}

\author{
Amelia Amanda ${ }^{\varpi}$, Anggraeni Anggraeni, Retno Purnama Irawati, Ria Riski Marsuki \\ Prodi Pendidikan Bahasa Mandarin, Jurusan Bahasa dan Sastra Asing, Fakultas Bahasa dan Seni, \\ Universitas Negeri Semarang, Indonesia
}

Keywords:

phonology, lexical, film,

Mandarin Chinese dialect,

Mandarin Taiwan dialect

\section{Info Artikel}

\begin{abstract}
Abstrak
Bahasa Mandarin merupakan bahasa dengan penutur terbanyak di dunia, termasuk merupakan bahasa nasional yang digunakan di Taiwan. Meskipun berasal dari sumber yang sama yaitu Beifanghua, namun terdapat perbedaan yang dapat dijumpai diantara keduanya terutama pada aspek fonologi dan leksikal. Untuk itu peneliti melakukan penelitian dengan menggunakan sumber data berupa film untuk membahas perbedaan yang ditemukan dalam film tersebut.

Tujuan dari penelitian ini yaitu: (1) Mendeskripsikan perbedaan fonologis dialek Mandarin Tiongkok dan dialek Mandarin Taiwan yang ditemukan di dalam film, (2) Mendeskripsikan perbedaan leksikal dialek Mandarin Tiongkok dan dialek Mandarin Taiwan yang ditemukan di dalam film. Hasil penelitian dari total 85 kosa kata data fonologi yang ditemukan dalam film The Ex-File 3: The Return Of The Exes (Tiongkok) dan film Our Times (Taiwan) ditemukan perubahan konsonan dan nada yang meliputi konsonan $\mathrm{zh}[\mathrm{ts}]$, ch [ts'], sh [s] dimana dialek Mandarin Taiwan pelafalannya menyerupai konsonan $\mathrm{z}[\mathrm{ts}], \mathrm{c}\left[\mathrm{ts}^{\mathrm{c}}\right]$ dan $\mathrm{s}[\mathrm{s}]$, perubahan konsonan $\mathrm{r}[\mathrm{z}]$ menjadi 1 [1] dan pengurangan konsonan g [k] pada dialek Mandarin Taiwan, serta perubahan nada dimana dialek Mandarin Tiongkok didominasi oleh nada ringan sedangkan dialek Mandarin Taiwan lebih bervariasi tanpa mengubah arti kata.
\end{abstract}

\begin{abstract}
Mandarin is the most spoken language in the world, including the national language spoken in Taiwan. Even though they come from the same source, namely Beifanghua, there are differences that can be found between the two, especially in the phonological and lexical aspects. For this reason, researchers conducted research using a data source in the form of a film to discuss the differences found in the film. The objectives of this study were: (1) Describing the phonological differences between Mandarin Chinese dialects and Mandarin Taiwanese dialects found in the film, (2) Describing the lexical differences between Mandarin Chinese dialects and Mandarin Taiwanese dialects found in the film. The research results from a total of 85 vocabulary words of phonological data found in The Ex-File 3: The Return of the Exes (China) and Our Times (Taiwan) films found changes in consonants and tones including the consonants $z h$ [ts] , ch [ts '], sh [s] where the Chinese Taiwanese dialect is pronounced like the consonant $z[t s], c\left[t s^{\prime}\right]$ and $s[s]$, changes the consonant $r[z]$ to $l[l]$ and the reduction of the consonant $g[k]$ in the dialect Mandarin Taiwan, as well as the change in tone where the Mandarin Chinese dialect is dominated by light tones while the Mandarin Taiwan dialect is more varied without changing the meaning of the word.
\end{abstract}

\footnotetext{
Alamat korespondensi:

Gedung B9 Lantai 2 FBS UNNES

Kampus Sekaran, Gunungpati, Semarang, 50229

E-mail: a.ameliaamanda@gmail.com
}

P-ISSN 2528-5734

E-ISSN 2715-1611 


\section{PENDAHULUAN}

Di antara banyaknya bahasa yang ada, bahasa Mandarin adalah bahasa dengan unsur segmental yang sangat kaya. Menurut Chaer (2009:120) bunyi segmental ialah bunyi yang dihasilkan oleh pernafasan, alat ucap, dan pita suara. Dalam situsnya https://jagoMandarin.com// Baldwin Husin menjelaskan bahwa bahasa Mandarin dalam pengertian luas dapat diartikan sebagai dialek Beijing (hanzi sederhana：北方话； pinyin : Bëifānghuà) atau bahasa percakapan Utara. Beifanghua merupakan bahasa dengan kategori yang luas dan mencangkup beragam jenis dialek di sebagian besar bagian utara dan barat daya Tiongkok serta digunakan sebagai bahasa lokal sehari-hari masyarakat di daerah tersebut. Namun Beifanghua tidak hanya menjadi bahasa percakapan di utara Tiongkok melainkan juga menjadi dasar bagi Putonghua (普通话) dan Guoyu (国语). Putonghua merupakan bahasa resmi Tiongkok dan Guoyu adalah bahasa resmi Taiwan, keduanya merupakan bahasa standar yang didasarkan pada Beifanghua. Secara sempit istilah Putonghua (bahasa Tionghoa baku) digunakan oleh masyarakat Tiongkok untuk merujuk pada bahasa Mandarin standar sedangkan istilah Guoyu (bahasa nasional) digunakan di Taiwan untuk merujuk pada bahasa Mandarin. Keduanya memiliki makna yang sama namun hanya berbeda istilah saja.

Meskipun Putonghua dan Guoyu didasarkan pada sumber yang sama yaitu Beifanghua namun tentu terdapat perbedaanperbedaan yang dapat dijumpai terutama dari aspek fonologi dan leksikalnya. Menurut Chaer (1994:102) fonologi ialah bidang linguistik yang mempelajari, menganalisis dan membicarakan runtutan bunyi-bunyi bahasa. Bunyi dalam bahasa Mandarin menyangkut tiga aspek utama yaitu konsonan, vokal dan nada. Sedangkan untuk perbedaan leksikal Nadra \& Reniwati menjelaskan bahwa perbedaan leksikal adalah variasi atau perbedaan bahasa yang terdapat dalam bidang leksikon (2009:28).
Pelafalan dialek Mandarin Taiwan secara keseluruhan terdengar lebih lembut, tidak sejelas pelafalan dialek Mandarin Tiongkok. Hal ini seperti Inggris Amerika dan Inggris British. Terjadinya perbedaan pelafalan ini berkaitan dengan sejarah pada masa lampau dimana sebelum pindah ke Taiwan, sebagian besar para pendahulunya merupakan imigran yang berasal dari Selatan Tiongkok yang mana masyarakatnya menggunakan dialek lokal Hakka dan Hokkian. Dalam fonologi Bahasa Mandarin, konsonan /zh/ dan /z/ merupakan dua bunyi yang berbeda, sebagai contoh kata找 (zhăo) yang berarti 'mencari' dan早 (zăo) yang berarti 'pagi', penutur dialek Mandarin Tiongkok akan lebih bisa membedakan keduanya dari segi artikulasi karena pelafalannya lebih jelas, sedangkan pada dialek Mandarin Taiwan kata找 (zhăo) bisa dibaca mirip dengan 'zăo'. Meskipun bisa saja hal ini menyebabkan miskonsepsi, namun tidak akan menjadi masalah jika kedua penutur saling memahami maksud yang ingin disampaikan. Selain pelafalan, masyarakat Taiwan juga menggunakan istilah yang berbeda untuk mendeskripsikan hal yang sama. Penutur dialek Mandarin Taiwan menggunakan kata 計程車 (jìchéngchē) untuk menyebut "taksi", sedangkan kata "taksi" di Mandarin Tiongkok adalah 出租车 (chūzū chē).

Film yang menjadi sumber penelitian kali ini berjudul The Ex-File 3 : The Return Of The Exes (Hanzi sederhana：前任3：再见前任； pinyin： Qiánrén sān: zàijiàn qiánrén) dari Tiongkok dan Our Times (Hanzi sederhana：我的少女时代 ; pinyin : Wŏ de shàonŭ shídài) dari Taiwan. Film The Ex-File 3 : The Return of The Exes (前任3：再见前任). Menurut Wibowo dkk (2006:196) film adalah alat untuk menyampaikan berbagai pesan kepada khalayak melalui sebuah media cerita. Peneliti memilih kedua film tersebut berdasarkan diskusi dengan para ahli dengan mempertimbangkan diksi yang digunakan di dalamnya serta perbandingan dengan film-film yang lain. Penyampaian diksi 
yang kerap ditemukan dalam bahasa sehari-hari menjadikan kedua film tersebut sesuai untuk dijadikan sumber penelitian.

Penggunaan film sebagai sumber data juga dibantu oleh wawancara dan rekaman yang diperoleh dari hasil analisis fonologi simak catat film yang dibacakan oleh responden dari Tiongkok dan Taiwan dengan ciri khas dialek yang sama seperti di dalam film. Tujuan dari rekaman ini yaitu sebagai pembanding hasil pengumpulan data simak catat agar mendapatkan hasil yang lebih akurat dan juga sebagai penguat jika hasil yang ditemukan serupa. Untuk itu perlu digarisbawahi penelitian ini bukan semata-mata menjadikan film sebagai wakil dari dialek itu sendiri. Sesuai judul penelitian ini, peneliti membatasi permasalahan kepada perbedaan dialek Mandarin Tiongkok dan dialek Mandarin Taiwan yang terdapat dalam film saja.

\section{METODE}

Jenis penelitian yang digunakan pada penelitan kali ini adalah deskriptif kualitatif. Teknik pengumpulan data yang digunakan adalah triangulasi dengan teknik catat, teknik rekam dan wawancara.

\section{HASIL DAN PEMBAHASAN}

Hasil penelitian ini meliputi lima hal, yaitu: (1) Hasil pengumpulan data metode simak fonologi Film 1 dan 2; (2) Hasil pengumpulan data rekaman yang di reverse oleh responden Tiongkok dan Taiwan; (3) Analisis data simak catat dan rekaman fonologi; (4) Hasil wawancara narasumber Tiongkok, Taiwan dan Indonesia terhadap hasil analisis data final fonologi; (5) Hasil metode simak variasi leksikal Film 1 dan 2.

\section{Hasil Pengumpulan Data Metode Simak Fonologi}

Film 1

Berdasarkan hasil pengumpulan data Film 1 ditemukan 40 contoh kata yang dapat dibandingkan dengan pelafalan dialek Mandarin Taiwan. Pada penelitian kali ini peneliti mengambil beberapa kata pada setiap kategori fonologinya. Kategori tersebut terbagi menjadi konsonan zh [ts], ch [ts'], sh [s] dan r [z] peneliti mengambil lima contoh kata, konsonan $\mathrm{z}$ [ts], c [ts'] dan $s$ [s] masing-masing lima kata dan untuk perubahan nada ditemukan perbedaan nada sebanyak lima kata.

\section{Film 2}

Berdasarkan hasil pengumpulan data Film 2 ditemukan 45 contoh kata yang dapat dibandingkan dengan pelafalan dialek Mandarin Tiongkok. Beberapa kata tersebut terbagi menjadi sembilan jenis sesuai kategori fonologinya. Kategori tersebut yaitu untuk konsonan zh [ts], ch [ts $\left.{ }^{\mathrm{s}}\right]$, sh [s] dan $\mathrm{r}[\mathrm{z}]$ peneliti mengambil lima contoh kata, konsonan $\mathrm{z}$ [ts], c [ts'] dan s [s] masing-masing lima kata dan konsonan $\mathrm{g}$ [k] sebanyak lima kata serta untuk perubahan nada ditemukan lima kata.

\section{Hasil Pengumpulan Data Rekaman}

\section{Rekaman Film 1}

Berdasarkan data yang dikumpulkan jika dibandingkan dengan dialek Mandarin Taiwan dari responden Film 1 terdapat sebanyak 20 perbedaan konsonan yang terdiri dari fonem $\mathrm{zh}$, ch, sh dan $r$ serta lima perbedaan nada. Tidak ada perbedaan vokal. Lalu sebagai pembanding fonem $\mathrm{zh}$, ch dan sh peneliti menggunakan fonem $\mathrm{z}$, $\mathrm{c}$ dan $\mathrm{s}$ yang total berjumlah 15 konsonan. Digunakannya fonem tersebut sebagai pembanding dikarenakan untuk melihat apakah pelafalan fonem $\mathrm{zh}$, ch dan sh oleh responden Film 1 memiliki ciri-ciri khusus dengan fonem $z, c$ dan $s$. Hal ini juga berlaku untuk pengumpulan data pada rekaman Film 2 . Total ketiga kategori yang ditemukan pada kartu data berjumlah 40 .

\section{Rekaman Film 2}

Perbedaan antara dialek Mandarin Tiongkok yang terdapat pada film jika dibandingkan dengan dialek Mandarin Taiwan dari responden Film 1 terdapat sebanyak 25 
perbedaan konsonan yang terdiri dari fonem zh, ch, sh, g dan r serta lima perbedaan nada. Tidak ditemukan perbedaan vokal. Sebagai pembanding fonem $\mathrm{zh}$, ch dan sh peneliti menggunakan fonem $\mathrm{z}, \mathrm{c}$ dan $\mathrm{s}$ yang total berjumlah 15 konsonan. Jadi total kedua kategori yang terdiri dari konsonan dan vokal berjumlah 45 .

\section{Hasil Analisis Data Simak Catat dan Rekaman}

\section{Analisis Fonologi Film 1}

Berdasarkan analisis dapat disimpulkan bahwa pelafalan konsonan $\mathrm{zh}$ [ts], ch [ts'] dan sh [s] yang termasuk dalam kategori konsonan suara ujung lidah belakang (舌尖后音 shéjiānhòuyīn) dalam pelafalan responden Taiwan sama seperti kategori suara ujung lidah depan (舌尖前音 - shéjiānqiányīn) alias平舌音píng shé yīn, yaitu konsonan $\mathrm{z}$ [ts], c [ts'] dan $\mathrm{s}$ [s]. Perbedaan yang jelas ditandai dari posisi lidah. Pada pelafalan zh [ts], ch [ts'], sh [s] oleh responden Taiwan posisi lidah direntangkan rata, menghadap atau dekat dengan bagian belakang gigi atas, sehingga lafal yang keluar menjadi $\mathrm{z}$ [ts], $\mathrm{c}$ [ts'] dan $\mathrm{s}$ [s].

Peleburan konsonan menjadi $\mathrm{r}$ [z] pada pelafalan responden Taiwan tidak ada sama sekali, terdapat kemungkinan bahwa hal ini dikarenakan penutur yang bicara dengan cepat sehingga terkesan seperti terdapat peleburan konsonan menjadi $r$ [z]. Dikarenakan hal tersebut masih berupa asumsi maka peneliti akan menggunakan data dari metode pengumpulan data yang lain (wawancara). Kemudian yang terakhir yaitu perubahan nada, terdapat satu perubahan nada keempat dan tiga nada ringan, beberapa kata dalam dialek Taiwan memiliki pelafalan nada yang berbeda namun tidak berarti mengubah makna dari kata tersebut.

\section{Analisis Fonologi Film 2}

Berdasarkan analisis dapat disimpulkan bahwa pelafalan konsonan zh [ts], ch [ts'] dan sh [s] yang termasuk dalam kategori konsonan suara ujung lidah belakang (舌尖后音 - shéjiānhòuyīn) pada pelafalan responden Tiongkok berbeda dengan kategori suara ujung lidah depan (舌尖前音 - shéjiānqiányīn) yaitu konsonan $\mathrm{z}$ [ts], $\mathrm{c}$ [ts'] dan s [s]. Pelafalan 尧犸舌音- qiào shé yīn (konsonan : zh [ts], ch [ts'] dan sh [s]) lebih berat, berbeda halnya dengan bunyi pelafalan konsonan tersebut di dalam Film 2 yang mirip seperti $\mathrm{z}$ [ts], c [ts'] dan s [s].

Peniadaan konsonan $\mathrm{g}[\mathrm{k}]$ menunjukkan bahwa hal ini erat kaitannya dengan dialek lokal dari Taiwan yaitu Minnanhua atau lebih dikenal dengan Hokkian. Untuk perubahan konsonan $r$ [z] menjadi 1 [1] dapat ditarik kesimpulan bahwa perbedaan tersebut dipengaruhi oleh daerah dimana penutur berasal, dalam artian terdapat pengaruh yang kuat oleh dialek lokal sehingga pelafalannya berbeda dengan responden Tiongkok yang menggunakan Beifanghua. Seperti halnya analisis rekaman Film 1, pada analisis rekaman Film 2 kategori nada juga memiliki perbedaan-perbedaan yang bisa ditelaah sehingga dapat disimpulkan bahwa antara dialek Taiwan dan dialek Tiongkok memang ada perbedaan nada yang tidak mengubah arti dari kata tersebut.

\section{Hasil Wawancara Narasumber Tiongkok, Taiwan dan Indonesia.}

Wawancara berisikan pertanyaan tentang perbedaan fonologi berdasarkan hasil data analisis simak catat dan rekaman. Tujuan dari wawancara ini adalah untuk menguji dan menguatkan data analisis sebelumnya yaitu metode simak catat dan rekaman. Wawancara dilakukan dengan total enam narasumber yang telah ditentukan dengan teknik purposive sampling.

Hasil wawancara menunjukkan bahwa pada kedua film terdapat perbedaan dari bidang fonologi yaitu konsonan /zh/, /ch/, /sh/ dimana pelafalan konsonan tersebut pada dialek Tiongkok lebih berat dan tebal. Konsonan /zh/, /ch/, /sh/ pada dialek Taiwan lebih menyerupai konsonan /z/, /c/, /s/. Kemudian untuk konsonan /z/, /c/, /s/ pada ketiga analisis tidak ditemukan ciri-ciri tertentu dengan pelafalannya pada dialek Mandarin Taiwan dan Tiongkok. Selanjutnya tidak ada peleburan 
konsonan /r/ pada dialek Mandarin Tiongkok. Adapun pengurangan konsonan /g/ pada dialek Taiwan pada kata-kata tertentu, ditemukan juga perubahan konsonan / $\mathrm{r} /$ menjadi /// pada dialek Taiwan seperti pada kata燃烧 (ranshao) dan人家 (renjia) menjadi "lanshao" dan "lenjia". Yang terakhir adalah perbedaan nada, mayoritas kata yang ditemukan di kategori ini pada dialek Tiongkok merupakan nada ringan dan nada keempat sedangkan pada dialek Taiwan justru lebih bervariasi namun tidak menunjukkan adanya perbedaan makna.

\section{Hasil Metode Simak Leksikal Film 1 dan Film 2}

Hasil analisis ditemukan bahwa pada Film 1 dan Film 2 jika digabung ditemukan sejumlah 61 kosa kata variasi leksikal. Adapun beberapa kata merupakan kata yang khas dari bahasa setempat, sehingga hanya digunakan oleh penduduk yang tinggal di daerah tersebut. Kosa kata tersebut meliputi "dan" dalam dialek Mandarin Tiongkok dan Taiwan masingmasing和 (hé) dan 和 (hàn), kata "sampah" yaitu 垃圾 (lājī) dan 垃圾 (lèsè), kata “mengunduh" yaitu 下载 (xiàzài) dan 下載 (dāngluò).

Lain halnya dengan pengaruh dialek lokal yaitu Hokkian pada beberapa kata dalam dialek Mandarin Taiwan. Di antaranya meliputi "melepaskan" pada dialek Mandarin Tiongkok dan Taiwan masing-masing卸 (xiè) dan 卸 (sià), kata "kehidupan" yaitu世 (shì) dan 世 (sì) serta kata "keramaian" yaitu众 (zhòng) dan 眾 (tsìng). Beberapa contoh keberagaman penemuan variasi leksikal pada penelitian ini menunjukkan adanya beberapa kosa kata yang hanya bisa digunakan di daerah setempat.

\section{SIMPULAN}

Berdasarkan hasil penelitian tentang analisis dialek Mandarin Tiongkok dan dialek Mandarin Taiwan dari film The Ex-File 3: The Return Of The Exes (Tiongkok) dan film Our Times (Taiwan), maka dapat disimpulkan:

\section{Berdasarkan analisis perbedaan fonologi}

kedua film dari total 85 kosa kata terdapat perubahan konsonan dan nada yang meliputi konsonan zh [ts], ch [ts'], sh [s] dimana dialek Mandarin Taiwan pelafalannya menyerupai konsonan $\mathrm{z}$ [ts], $\mathrm{c}$ [ts'] dan s [s] tanpa ciri-ciri khusus. Perubahan konsonan $\mathrm{r}$ [z] menjadi 1 [1] dan pengurangan konsonan $\mathrm{g}[\mathrm{k}]$ pada dialek Mandarin Taiwan yang tidak ditemukan pada dialek Mandarin Tiongkok, serta perubahan nada dimana dialek Mandarin Tiongkok didominasi oleh nada ringan sedangkan dialek Mandarin Taiwan lebih bervariasi. Perubahan nada tersebut tidak mengubah arti atau makna dari sebuat kata.

\section{Variasi leksikal dari kedua film}

Ditemukan sejumlah 61 kosa kata yang menunjukkan keberagaman leksikon yang muncul dari kedua film. Dari beberapa variasi terdapat kosa kata yang hanya digunakan di Film 1 maupun Film 2, yakni meliputi kata "dan" dalam dialek Mandarin Tiongkok dan Taiwan masing-masing和 (hé) dan 和 (hàn), kata "sampah" yaitu 垃圾 (lājì) dan 垃圾 (lèsè), kata "mengunduh" yaitu 下载 (xiàzài) dan 下載 (dāngluò). Kemudian ditemukan variasi leksikal yang dipengaruhi oleh dialek Hokkian pada beberapa kata dalam dialek Mandarin Taiwan, yaitu kata "melepaskan" pada dialek Mandarin Tiongkok dan Taiwan masing-masing 卸 (xiè) dan 卸 (sià), kata "kehidupan" yaitu 世 (shi) dan 世 (si) serta kata "keramaian" yaitu 众 (zhòng) dan 眾 (tsìng). Seperti halnya kosa kata sebelumnya, variasi leksikal yang ditemukan pada tiga kata ini memiliki dasar karakter yang sama namun dengan penyebutan yang berbeda.

\section{DAFTAR PUSTAKA}

Castello, Dominic. 2013. Cantonese and Mandarin: Different Dialects or Different Languages? University of Birmingham.

Chaer, Abdul. 1994. Linguistik Umum. Jakarta: Rineka Cipta.

Hendri W, Yusin. 2014. Sang Naga dari Timur. Jakarta: PT Gramedia Pustaka Utama. 
Amelia Amanda dkk. / Longda Xiaokan: Journal of Mandarin Learning and Teaching 4 (1) (2021)

Hidayah. 2013. Analisis Kesalahan Pelafalan Konsonan (声母) $z, c, s, z h, c h, c h$, sh dan $r$ dalam Kosakata Bahasa Mandarin di Kelas X SMA YSKI Semarang. Pendidikan Bahasa Mandarin. Fakultas Bahasa dan Seni. Universitas Negeri Semarang.

Husin, Baldwin. 2014. Mandarin adalah Bahasa dengan Penulisan Huruf Tersulit di Dunia?, (Online), (https://www.jagomandarin.com/blog/2014/ 1/17/mandarin-adalah-bahasa-denganpenulisan-huruf-tersulit-di-dunia, diakses pada 14 November 2018).

Junawaroh, Siti. 2016. Deskripsi Perbedaan Fonologi Bahasa-Bahasa di Wilayah Barat Provinsi Jawa Tengah. HUMANIKA Vol. 23 No. 2 ISSN 1412-9418.

Li, Huili. 2019. Bunyi Sengau Bahasa Indonesia dan Bunyi Sengau. KIPBIPA XI. ISSN: 2716-3792.

Miles, B. Mathew dan Michael Huberman. 1992. Analisis Data Kualitatif: Buku Sumber Tentang Metode-metode Baru. Jakarta: UI Press.

Mulyaningsih, Dwi Hadi. 2014. Perbandingan Fonologi Bahasa Indonesia dan Bahasa Mandarin. Bahtera. Vol 13 No 1.

Sari, Novita. 2018. Perbedaan Pelafalan Bunyi Konsonan Apikopalatal (舌尖硬 Shéjiān ying’èyīn) dan Apikodental (舌尖齿音Shéjiān chìyin) Antara Bahasa Mandarin Putonghua dan Bahasa Mandarin Dialek Min Selatan. Sastra Cina. Fakultas Sastra. Universitas Darma Persada.

Wibowo, Fred. 2006. Teknik Program Televisi. Yogyakarta: Pinus Book Publisher.

Xiqiang, Xiao dan $\mathrm{Zhu}$ Min. 2008. Intensive Elementary Chinese Course a Comprehensive Book I. Beijing: Peking University Press. 